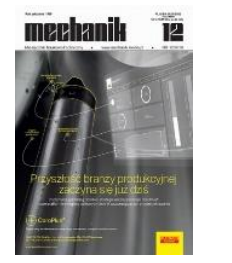

How to cite this article:

Authors: Stanisław Adamczak, Jacek Świderski, Tatiana Miller, Michał Wieczorowski, Ireneusz Chmielik

Title of article: "Principles of good metrological practice in order to ensure reliable measurements of the surface

structure"

Mechanik, No. 12 (2018)

DOI: https://doi.org/10.17814/mechanik.2018.12.196

\title{
Principles of good metrological practice in order to ensure reliable measurements of the surface structure
}

\author{
STANISŁAW ADAMCZAK \\ JACEK ŚWIDERSKI \\ TATIANA MILLER \\ MICHAŁ WIECZOROWSKI \\ IRENEUSZ CHMIELIK *
}

Prof. dr hab. inż. Stanisław Adamczak, adamczak@tu.kielce.pl, https://orcid.org/0000-0002-7797-6330 - Wydział Mechatroniki i Budowy Maszyn Politechniki Świętokrzyskiej, Kielce, Polska

Mgr inż. Jacek Świderski, swiderski@tu.kielce.pl, https://orcid.org/0000-0001-9791-9133 - Wydział Mechatroniki i Budowy Maszyn Politechniki Świętokrzyskiej, Kielce, Polska

Mgr inż. Tatiana Miller, tatiana.miller@ios.krakow.pl, https://orcid.org/0000-0001-7348-231X - Instytut Zaawansowanych Technologii Wytwarzania, Kraków, Polska

Prof. dr hab. inż. Michał Wieczorowski, michal.wieczorowski@put.poznan.pl, https://orcid.org/0000-0001-7526-8368 - Politechnika Poznańska, Poznań, Polska

Dr. inż. Ireneusz Chmielik, p.chmielik@taylor-hobson.pl - Taylor Hobson, Warszawa, Polska

The most important factors influencing obtaining reliable results of surface structure measurements are presented. The article presents the rules for the selection of an appropriate measurement method adapted to the nature of the measured surface and the advantages, disadvantages and limitations of measuring instruments. Principles of good metrological practice during the preparation of the device for carrying out measurements and performing the analysis in order to calculate the parameters of the of the surface structure were discussed.

KEYWORDS: measurement uncertainty, contact stylus scanning, surface texture

\section{Introduction}

Condition of geometric structure of the surface is one of the most important factors determining the proper functioning of products, and modern technologies allow for proper shaping of this structure in order to obtain the required properties. Verification of compliance with the requirements for the geometric structure of the surface is based on measurements and determined parameters characterizing its properties. Along with the development of manufacturing technology, there has been a dynamic development of new methods for measuring the geometric structure of the surface and measuring instruments using these methods in recent years. These solutions are increasingly used in both industrial practice and scientific research.

According to the classification system presented in PN-EN ISO 25178-6:2011 [1], the methods of measuring the geometric structure of the surface are divided into three classes:

- linear profiling methods,

- spatial topography methods,

- integrated area methods.

The analysis presented in the paper concerns the first two classes of methods - due to the fact that the methods belonging to the first class provide data in the form of a linear profile $z(x)$, and those belonging to the second class - data in the form of spatial topography $z(x, y)$.

A correctly performed measurement should be characterized by consistency, reliability and usability.

Measurement consistency should be understood as a property of the measurement result, at which this result can be associated with a reference through a documented, uninterrupted chain of calibrations, each of which contributes to measurement uncertainty [2]. For measurements of the geometric surface structure, the reference is the definition of the unit of measure for length through its practical implementation. PKN-ISO/IEC 
"Guide 99 International metrology dictionary. Basic concepts and associated general terms (VIM)" do not provide any definition of a reliable measurement result. This term is meant a result, in which the range $x \pm U$ (where: $x$ - measured value, $U$ - extended measurement uncertainty) is the true value, i.e. the result that can be reliable. A useful measurement result should be one that can be used to make a specific decision. Only reliable and useful measurement results can be the basis for inferring the compliance or non-compliance with specifications, or for the correctness of accepted scientific hypotheses.

Necessary element to ensure consistency, reliability and usefulness of measurement is reliable estimation of its uncertainty. This requires identifying potential sources of error that will contribute the most to the uncertainty budget. Another element is compliance with the principles of good metrological practice (contained in the measurement procedures) to ensure that the uncertainty ranges of individual components adopted in the budget are not exceeded.

\section{Criteria for choosing a method for measuring the geometric structure of a surface}

Basic criteria that should be followed when choosing a method for measuring the geometric structure of the surface are (in succession): dimensions and mass of the measured object, physical properties of the material from which the tested element was made, and nature of the measured inequalities.

The first criterion is related to the capabilities of the instrument, resulting from its measuring space and permissible load capacity of the measuring table. Failure to meet this criterion by the object being measured clearly excludes the use of a given device.

The second criterion concerns physical properties of surfaces, such as hardness, and optical properties, such as reflectivity and absorption. The use of contact profilometry with a mapping blade for measuring elements made of materials with low hardness may damage the surface, even if the allowable pressure of the measuring tip is not exceeded. The use of optical methods for measuring surfaces with low reflectivity results in the occurrence of a large number of unmeasured points, which increases the uncertainty of such measurement.

The third criterion is related to the nature of inequalities occurring on the measured surface, which can be described by the amplitude, distance of the inequality or slope inclination. In this case, the measurement method should be selected in terms of achievable sampling steps in the $O X$ and $O Y$ axes and resolution in the $O Z$ axis.

Generally, it should be assumed that for measuring inequalities with the smallest amplitude and the smallest wavelength, microscopes with a scanning probe are used, e.g. atomic force microscopes. In the case of a group of optical and contact devices, the choice is not so straightforward, because in addition to the possibility of horizontal sampling and resolution in vertical axis, the slope mapping efficiency and mechanical filtration resulting from the mapping blade geometry, are also important.

\section{Preparation of contact profilometer for measurements}

The first characteristic to be measured before actual measurements are the pressure of the mapping blade. Verification of the static contact force exerted by the blade mapping the measured surface is important because of the effects of applying too much or too little force. Too high force can cause plastic deformations of the surface layer of the measured object and its damage (fig. 1), and too low force in connection with higher speeds of the measuring tip movements may result in the momentary loss of contact of the mapping blade with the measured surface and thus the mapping of unevenness.

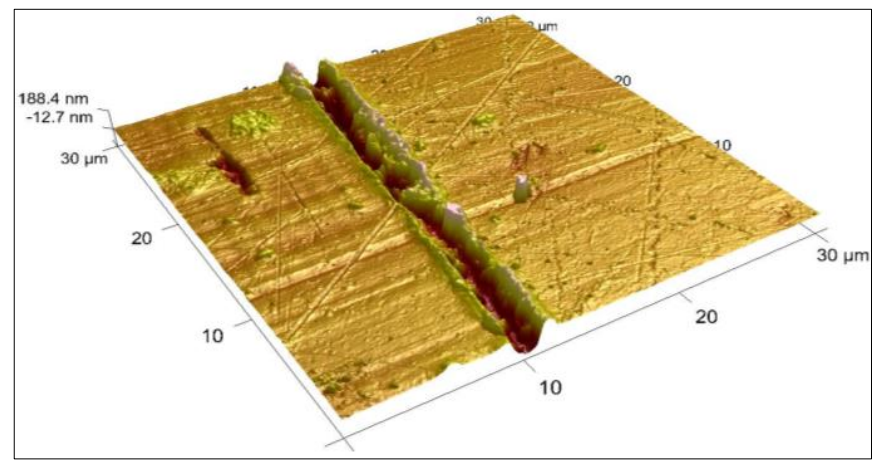

Fig. 1. Damage to the measured surface caused by too much pressure from the mapping blade 
To control the pressure force, a laboratory scale with a resolution of $0.01 \mathrm{~g}$ is used. The pressure force should be measured in the middle position of the measuring head of the profilometer measuring head. The maximum allowable pressure should not exceed $0.75 \mathrm{mN}$.

\section{Checking the status of the mapping blade}

Diamond blade reflecting the contact profile is an element directly in contact with the measured surface, thus the quality of the mapping of uneven profile on the measured element depends on its geometry (cone angle $\alpha$ and radius $r_{\text {tip }}$ ) and potential damage. Periodic checking of the condition of the mapping blade is necessary due to the fact that even during correct operation of the device, its natural wear occurs. Condition of the blade can be checked using the PRB type standard - razor blade [3]. The standard should be measured with the lowest feedrate possible for the given device.

Checking the state of the mapping blade by analyzing the results of measurement performed on the razor blade consists in determining the radius $r_{\text {tip }}$ of the mapping blade. The rounding radius of the razor blade does not exceed $0.1 \mu \mathrm{m}$. The profile recorded during the measurement has a radius that is the sum of radius of the mapping blade and the razor blade. Since the blade radius of razor blade is much smaller than that of the mapping blade, it can be assumed that the radius recorded is approximately equal to the radius of the mapping blade. The recorded profile will also show any damage to the blade, which may be the basis for its withdrawal from further operation. Value of the mapping rounding radius has a large impact on the mechanical filtering of measured inequalities and obtained values of roughness parameters.

\section{Dynamic noise measurement}

Measurement of the surface profile of the AFL type standard [3] (Class I flat interference plate with a permissible flatness deviation of $30 \mathrm{~nm}$ ) enables determination of measurement noise, which is the result of vibrations of the profilometer shift assembly, noise generated by the device's electronic assemblies, and external factors, e.g. vibration on the measurement process. Fig. 2 shows the results of noise measurements for two different contact profilometers.

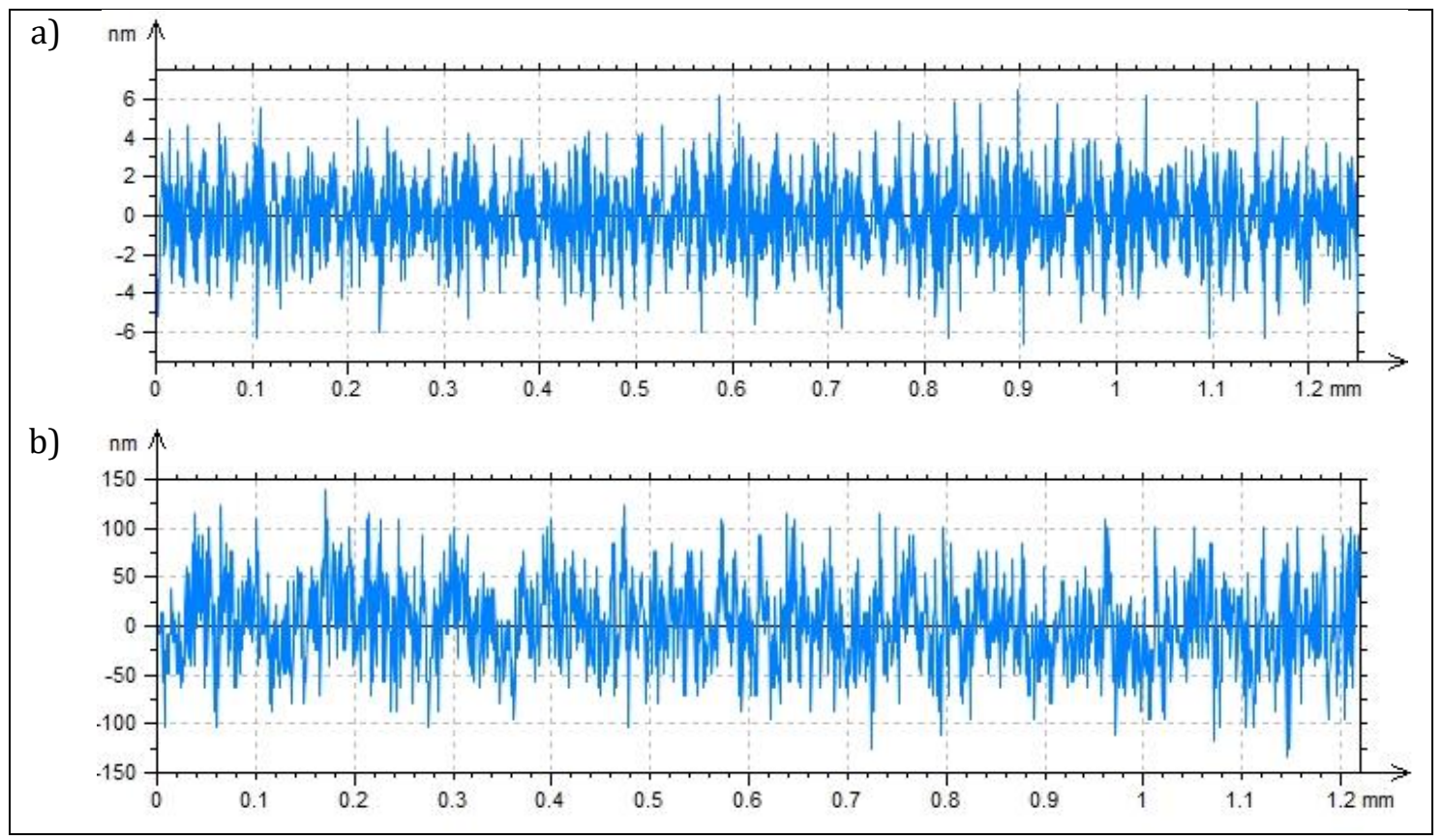

Fig. 2. Noise measurement results for: a) profilometer with an interferometric head, b) profilometer with an induction head

Noise values for these devices, assessed by the $R q$ parameter $\left(\lambda_{c}=0.025 \mathrm{~mm}\right)$ differ significantly and are respectively: for the first device $-R q=1.6 \mathrm{~nm}$, and for the second $-R q=33.6 \mathrm{~nm}$.

Measurement of surface stereometry of the AFL type standard allows for determining the impact of cyclical changes in ambient temperature on the results of surface stereometry measurements. Such results in the form 
of an isometric image and a separated profile in the $Y$ axis along with changes in ambient temperature are shown in fig. 3.

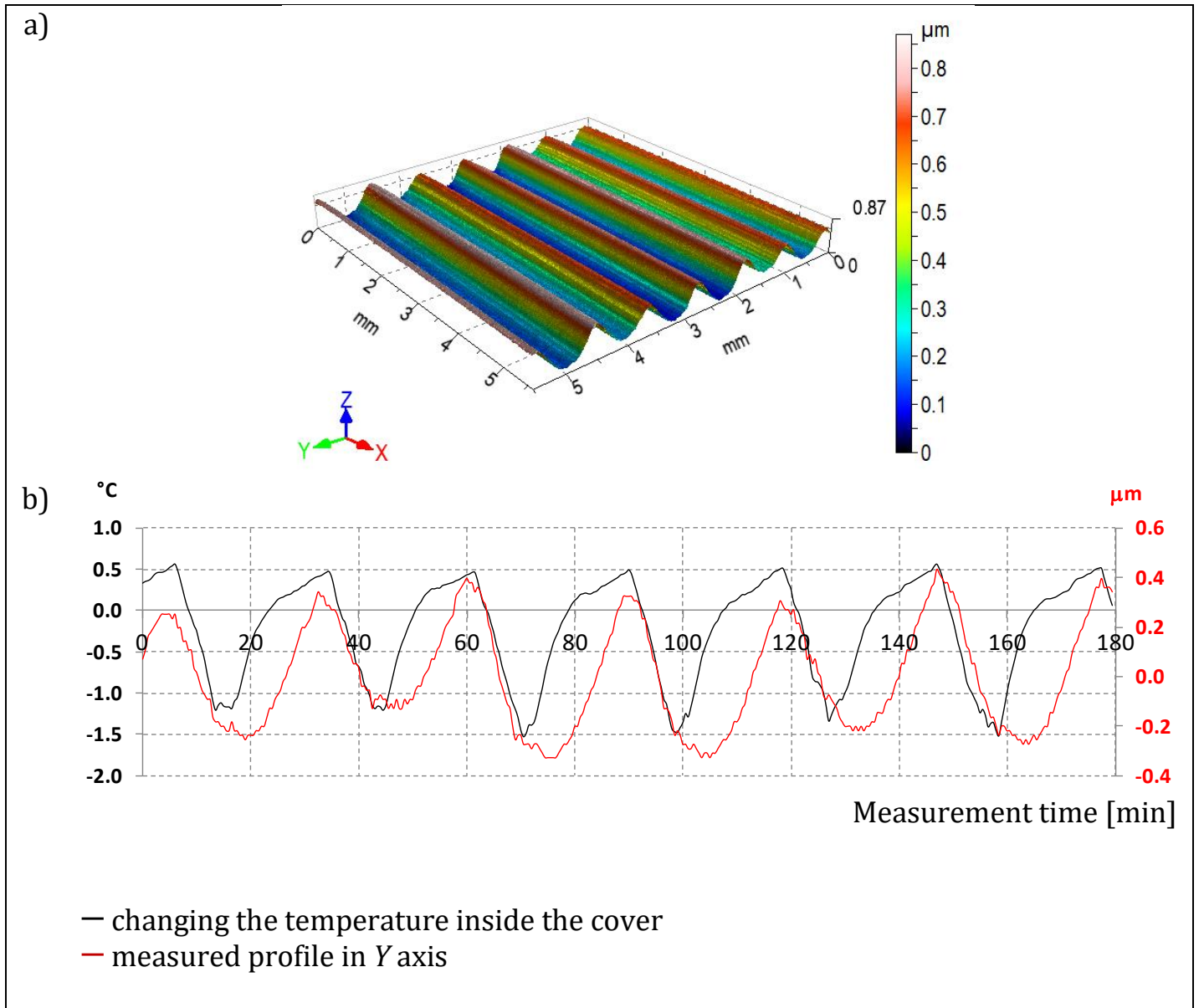

Fig. 3. Measurement results of the AFL type standard: a) isometric image, b) extracted profile in the $Y$ axis and ambient temperature changes

\section{Performing the calibration}

The aim of calibrating the device is to ensure measuring consistency. A wide range of standards for calibrating the surface topography measuring instruments are presented in the standards $[3,5,6]$ :

- PN-EN ISO 25178-70: 2014 SGP: Spatial - Part 70: Material standards,

- PN-EN ISO 25178-701: 2010 SGP: Spatial - Part 701: Calibration and standards for contact instruments with a mapping blade,

- PN-EN ISO 5436-1: 2000 SGP: Profile method - Standards - Part 1: Material standards.

The first of the standardization documents provides for 24 types of material profile models. Some of them have their counterparts in the other two documents. Calibration is necessary to carry out any adjustment of the device, i.e. to carry out operations aimed at ensuring that the measured values correspond to the correct indications. After adjustment, the measuring system should be recalibrated [2].

The scope of calibration and the choice of material standards depend on the measuring range and whether the profilometer is to be used for measuring the profile or also for measuring the surface stereometry. In the case of profile measurements, it is necessary to calibrate in the $X$ and $Z$ axes using appropriately selected standards.

For profilometers with large measuring range in the $Z$ axis, calibration combined with the determination of correction factors is carried out on an ASP (hemisphere) type standard. The course of such calibration and the profile obtained after removing the nominal shape of the standard is shown in fig. 4. Such measurement also allows for checking the correct functioning of the measuring head and state of the mapping blade.

In the case of profile-only measurements, it is sufficient to use type A standards for calibrating the $Z$ axis and type $\mathrm{C}$ standards for calibrating the $X$ axis. For surface stereometry measurements, it is justified to use standards from a new group, e.g. ACG and AIR, the isometric images of which are presented in fig. 5. 

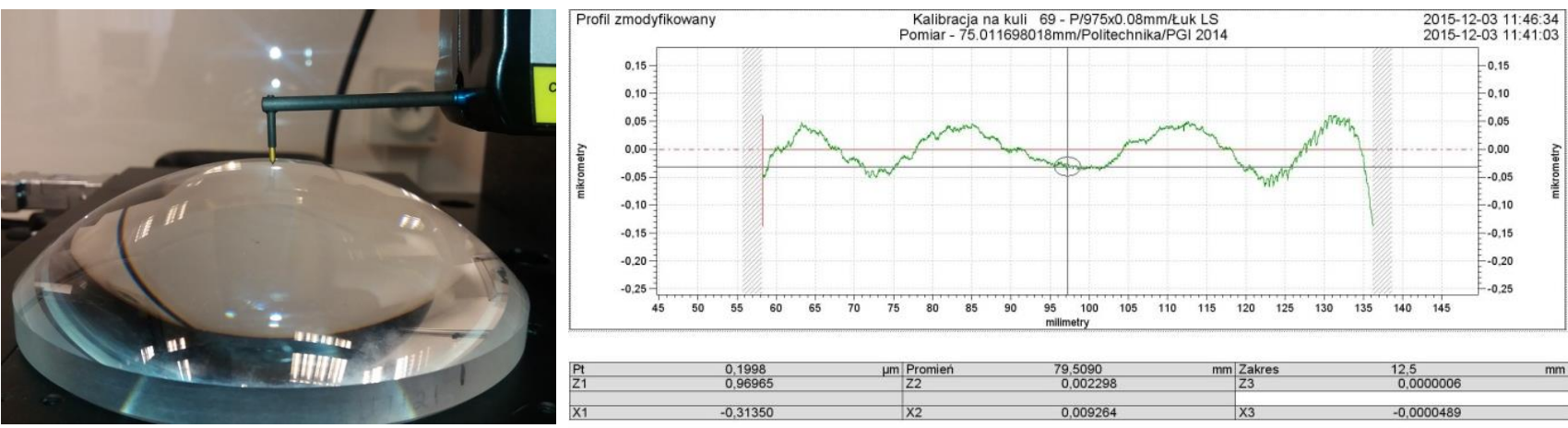

Fig. 4. Profile calibration process using an ASP type standard (left) and result in the form of a profile after removing the nominal shape (right)
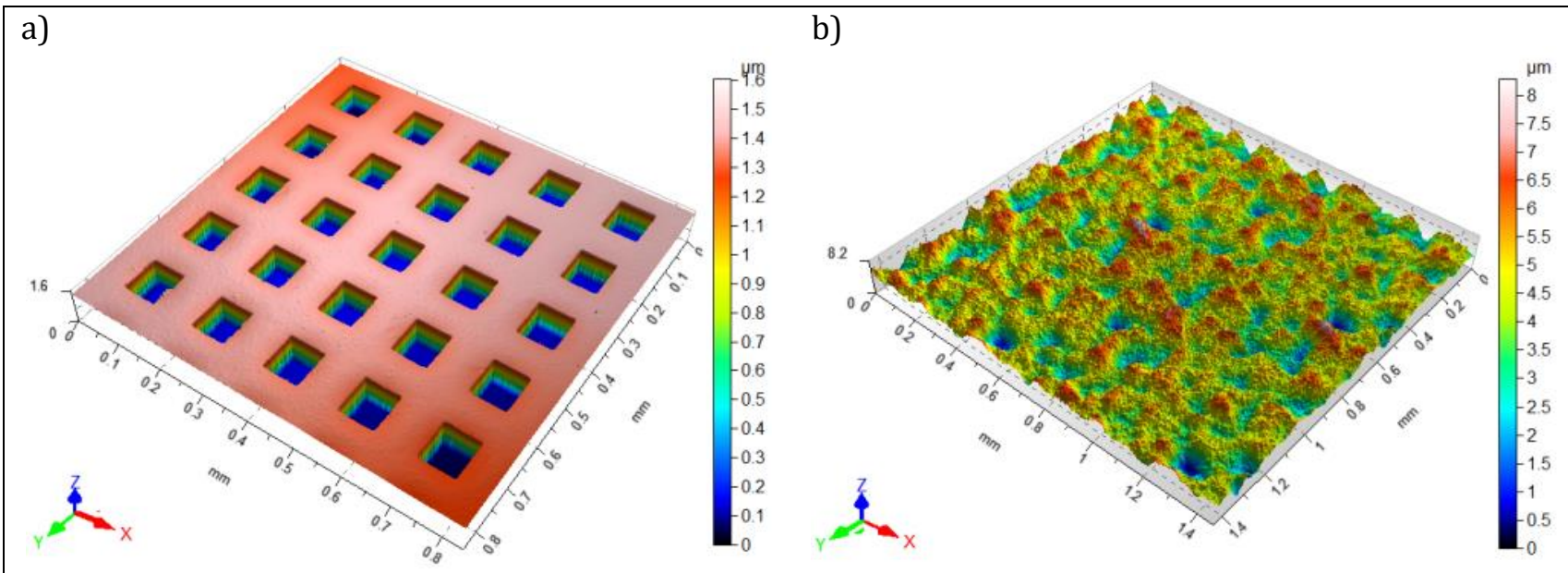

Fig. 5. Standards for calibration of instruments for measuring the surface stereometry: a) ACG type, b) AIR type

\section{Performing the measurement}

The correct way to carry out measurements is decisive for obtaining reliable results. Before starting the measurement, the surface of the measured element should be thoroughly cleaned. Positioning the workpiece on the profilometer table should ensure that the mapping blade moves perpendicular to the machining marks. Before starting the measurement, check the condition of the device's vibration isolation system.

The main measurement parameters that are influenced by the person making it are: feedrate of the mapping blade, sampling distance in the $X$ and $Y$ axes and length of the measuring segment.

Available mapping blade feedrates in modern profilometers range from 0.1 to $2 \mathrm{~mm} / \mathrm{s}$. The tendency to use higher feedrates results from the possibility of shortening the measurement time of surface stereometry - in the case of using contact profilometers, the measurement time may be even several hours.

The use of too high speed may cause the contact of the measuring tip with the measured surface to be lost and thus the mapping of unevenness incorrectly.

The effects of using too high blade feedrate are shown on the example of the $\mathrm{C}$ type standard measurement. Fig. 6 shows a fragment of the standard profile for the feedrates $v=0.25 ; 0.5 ; 1$ and $2 \mathrm{~mm} / \mathrm{s}$. From the blade feedrate $v=1 \mathrm{~mm} / \mathrm{s}$, the measured profile shows the effects of loss of contact of the measuring tip with the measured surface, namely disappearing pulsations. The impact of feedrate on the obtained values of amplitude parameters is presented in tab. I.

The effect of using too high blade feedrate in relation to the nature of the measured surface is illustrated in fig. 7, showing isometric images of the ground surface, obtained for the feedrates $v=0.5 \mathrm{~mm} / \mathrm{s}$ and $v=2 \mathrm{~mm} / \mathrm{s}$. In tab. II, the $S a$ parameter values are given depending on the feedrate used. Up to the feedrate $v=0.5 \mathrm{~mm} / \mathrm{s}$, the $S a$ parameter values are very similar.

The speed of the mapping blade also affects the value of the measuring noise. Results of noise measurements carried out on an AFL type standard are summarized in Tab. III. As it can be seen, up to the speed of $v=0.5$ $\mathrm{mm} / \mathrm{s}$, the noise value measured with the $R q$ parameter value remains at a similar level. Above this feedrate level, the measurement noise increases several times. 
An important parameter that affects the results is the sampling interval used. The effect of this parameter is shown for a profile measured with a sampling interval of $\Delta x=0.125 \mu \mathrm{m}$ - see fig. 8 . The obtained parameters are presented in tab. IV.

In order to obtain different sampling intervals, every second line was deleted from the text file containing the profile coordinates in succession. As a result, profiles with sampling intervals were obtained: $\Delta x=0.25 \mu \mathrm{m}$, $\Delta x=0.5 \mu \mathrm{m}$ and $\Delta x=1 \mu \mathrm{m}$. Fig. 9 presents fragment of the profile between 0.5 and $0.6 \mathrm{~mm}$ for the sampling interval $\Delta x=0.125 \mu \mathrm{m}$ and $\Delta x=1 \mu \mathrm{m}$. Comparison of two profiles shows that the profile obtained for a smaller sampling interval maps the unevenness of the measured surface much better.

Fig. 10 compares the parameters calculated on the basis of data obtained for the sampling interval $\Delta x=0.25$; 0.5 and $1 \mu \mathrm{m}$ in relation to the parameters calculated on the basis of the measured profile with the sampling interval $\Delta x=0.125 \mu \mathrm{m}$. All roughness profile amplitude parameters $-R p, R v, R z, R c, R t, R a$ and $R q$ - and the $R d q$ parameter are reduced as the sampling interval increases. The largest change occurs for the $R d q$ parameter by as much as $32.8 \%$. For $R s k, R k u$ and $R S m$ parameters, their values increase as the sampling interval increases. The $R S m$ interval parameter is the most sensitive to changing the sampling interval - in this case, the increase of its value is $36.5 \%$ in relation to the initial sampling interval.

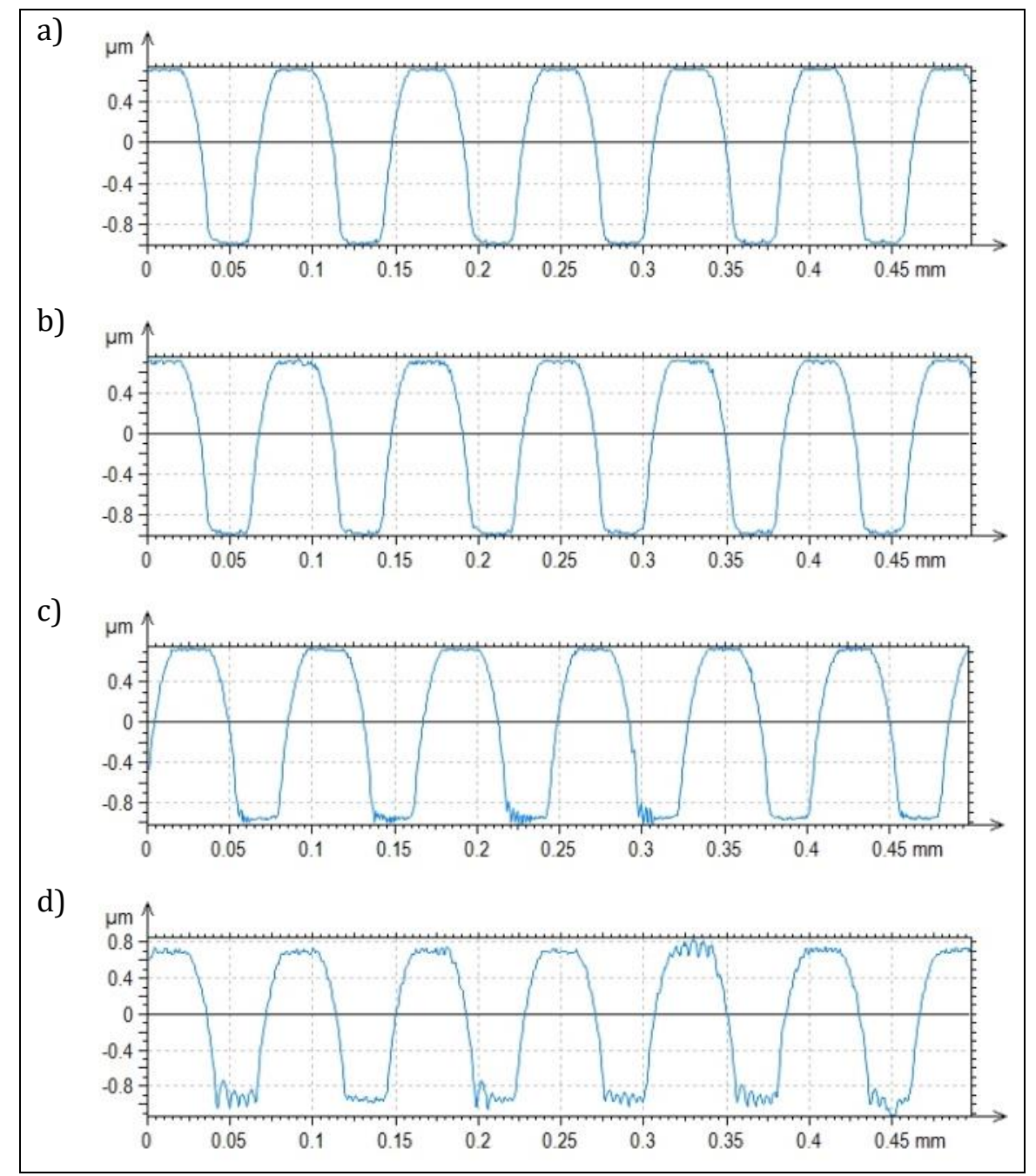

Fig. 6. Measured $C$ type standard profile for blade feedrate: a) $v=0.25 \mathrm{~mm} / \mathrm{s}$, b) $v=0.5 \mathrm{~mm} / \mathrm{s}$, c) $v=1 \mathrm{~mm} / \mathrm{s}$, d) $v=2 \mathrm{~mm} / \mathrm{s}$

TABLE I. Results of measurements of the C type standard as a function of the blade feedrate

\begin{tabular}{|c|c|c|c|c|c|}
\hline \multirow{2}{*}{ Parameter } & \multicolumn{5}{|c|}{$v[\mathrm{~mm} / \mathrm{s}]$} \\
\cline { 2 - 6 } & 0,10 & 0,25 & 0,50 & 1,00 & 2,00 \\
\hline$R p[\mu \mathrm{m}]$ & 0,772 & 0,774 & 0,776 & 0,821 & 0,953 \\
\hline$R v[\mu \mathrm{m}]$ & 0,986 & 0,986 & 0,988 & 1,005 & 1,077 \\
\hline$R a[\mu \mathrm{m}]$ & 0,668 & 0,067 & 0,666 & 0,666 & 0,661 \\
\hline
\end{tabular}




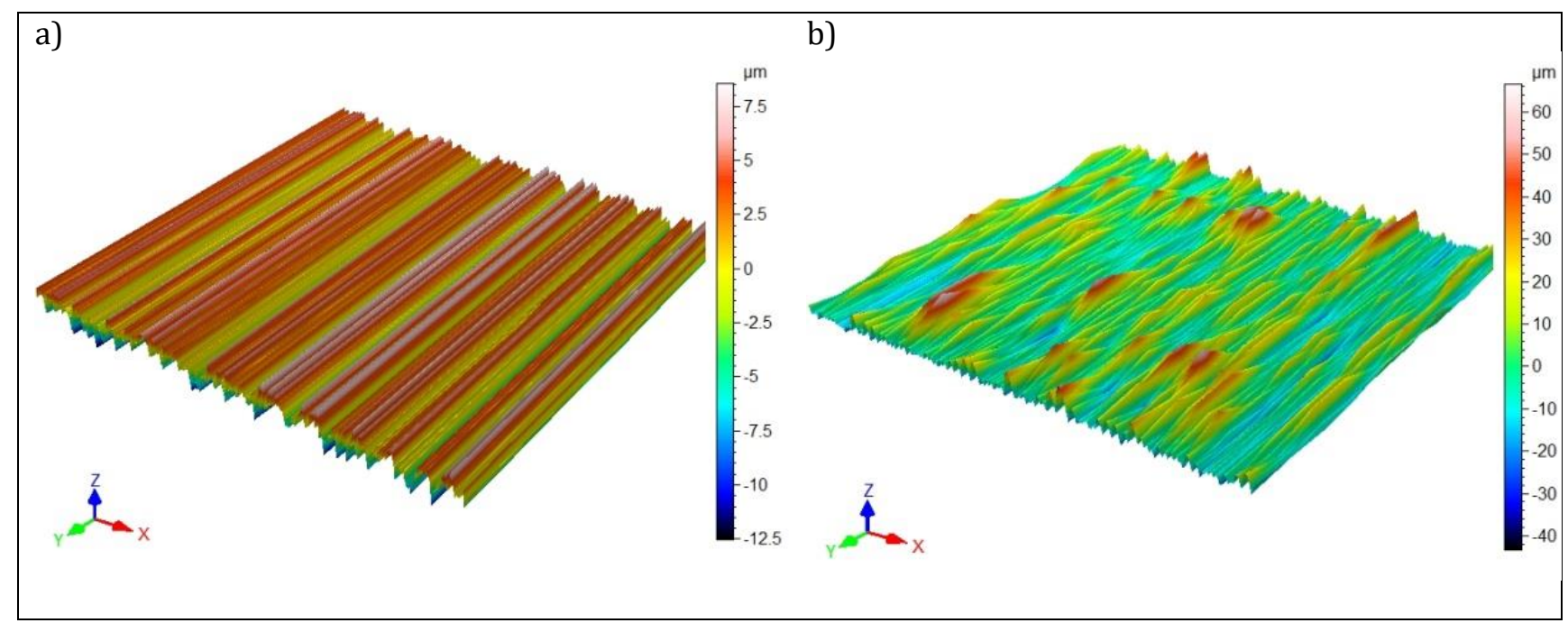

Fig. 7. Isometric image of the ground surface obtained as a result of measurement with the speed of the mapping blade: a) $v=0.5 \mathrm{~mm} / \mathrm{s}, \mathrm{b}) v=2 \mathrm{~mm} / \mathrm{s}$

TABLE II. Measurement results of $S a$ parameter for a ground surface as a function of the feedrate of the mapping blade

\begin{tabular}{|c|c|c|c|c|c|}
\hline \multirow{2}{*}{ Parameter } & \multicolumn{5}{|c|}{$v[\mathrm{~mm} / \mathrm{s}]$} \\
\cline { 2 - 6 } & 0,10 & 0,25 & 0,50 & 1,00 & 2,00 \\
\hline$S a[\mu \mathrm{m}]$ & 2,923 & 2,941 & 2,960 & 3,791 & 10,703 \\
\hline
\end{tabular}

TABLE III. Noise measurement results as a function of the mapping blade feedrate

\begin{tabular}{|c|c|c|c|c|c|}
\hline \multirow{2}{*}{ Parameter } & \multicolumn{5}{|c|}{$v[\mathrm{~mm} / \mathrm{s}]$} \\
\cline { 2 - 6 } & 0,10 & 0,25 & 0,50 & 1,00 & 2,00 \\
\hline$R q[\mathrm{~nm}]$ & 2,97 & 2,59 & 2,95 & 6,40 & 12,83 \\
$\left(\lambda_{c}=0,025 \mathrm{~mm}\right)$
\end{tabular}

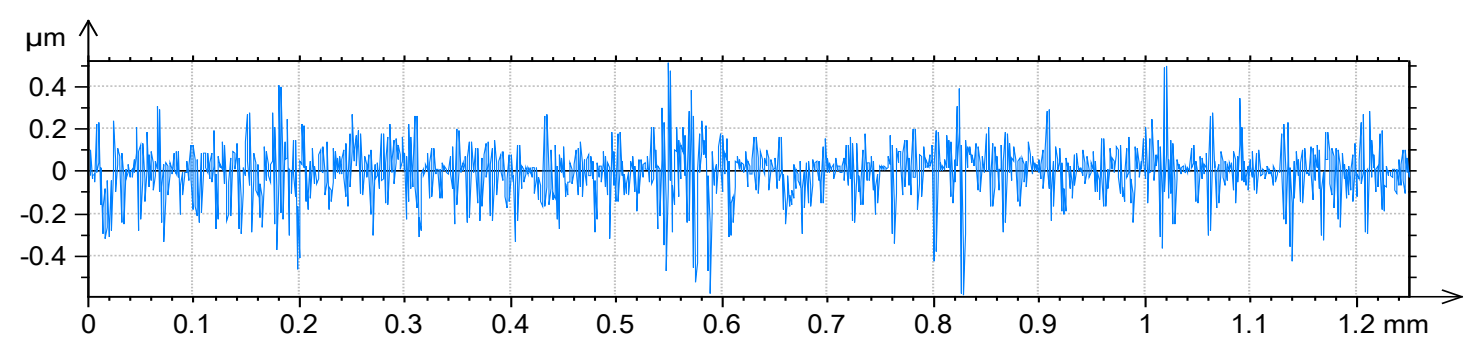

Fig. 8. Measured profile with sampling interval $\Delta x=0.125 \mu \mathrm{m}$

TABLE IV. Parameters of the measured profile for the sampling interval $\Delta x=0.125 \mu \mathrm{m}\left(\lambda_{s}=2.5\right.$, $\lambda_{\mathbf{c}}=0.25 \mathrm{~mm}$ )

\begin{tabular}{|c|c|c|c|c|c|c|c|c|c|c|}
\hline$R p[\mu \mathrm{m}]$ & $R v[\mu \mathrm{m}]$ & $R z[\mu \mathrm{m}]$ & $R c[\mu \mathrm{m}]$ & $R t[\mu \mathrm{m}]$ & $R a[\mu \mathrm{m}]$ & $R q[\mu \mathrm{m}]$ & $R s k$ & $R k u$ & $R S m[\mu \mathrm{m}]$ & $R d q\left[^{\circ}\right]$ \\
\hline 0.419 & 0.476 & 0.895 & 0.300 & 1.130 & 0.086 & 0.121 & -0.607 & 5.468 & 7.220 & 7.780 \\
\hline
\end{tabular}
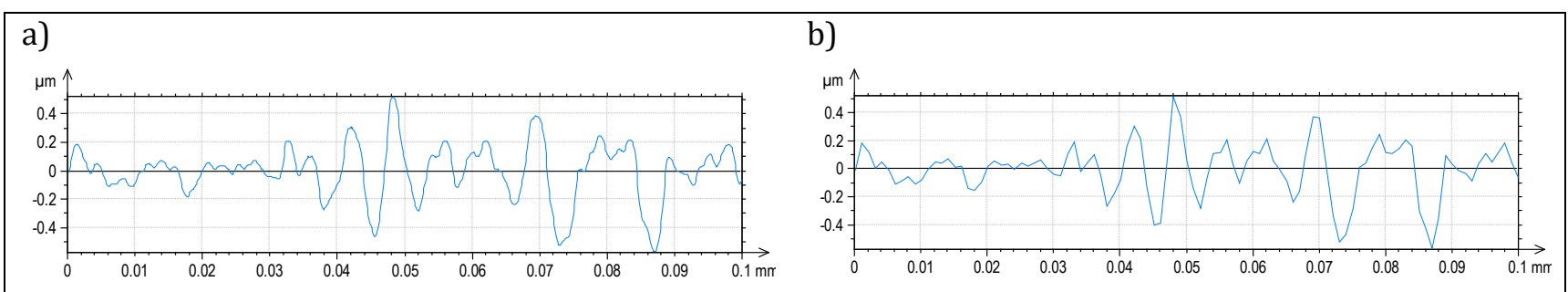

Fig. 9. Fragment of the profile between 0.5 and $0.6 \mathrm{~mm}$ : a) for the sampling interval $\Delta x=0.125 \mu \mathrm{m}$,

b) for the sampling interval $\Delta x=1 \mu \mathrm{m}$ 


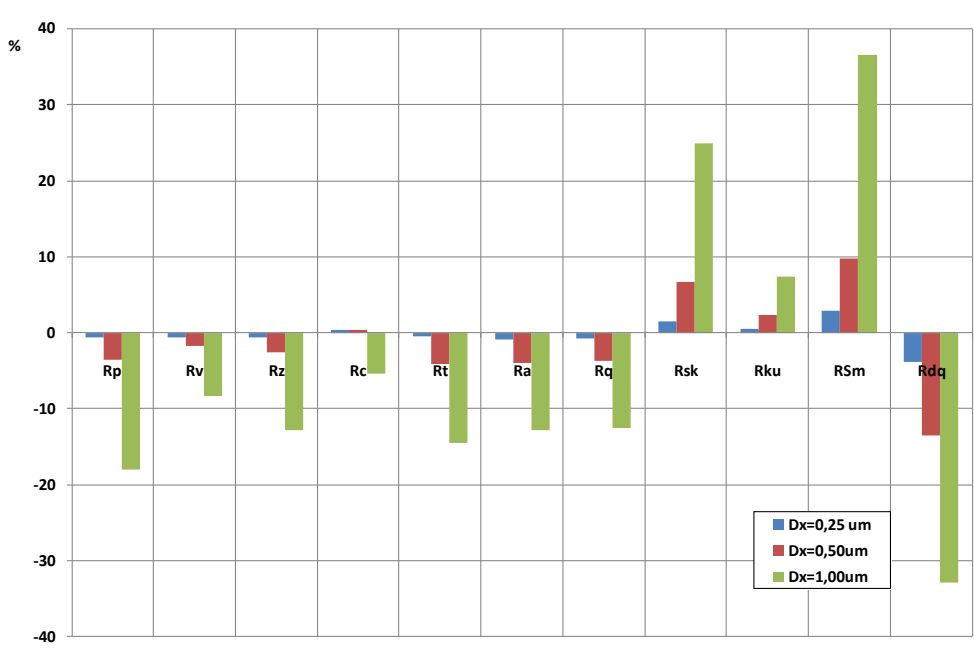

Fig. 10. Percentage change of parameter values obtained for sampling intervals $\Delta x=0.25 \mu \mathrm{m}, 0.5 \mu \mathrm{m}$ and $1 \mu \mathrm{m}$ in relation to the sampling interval $\Delta x=0.125 \mu \mathrm{m}$

A very important parameter that should be selected before starting the measurement is the length of the measuring section. The rules of this selection result from the nature of the measured surface (periodic or random surface) and the initial assessment of the obtained roughness profile parameters.

\section{Checking the software for the analysis of the geometric structure of the surface}

One of the potential sources of errors in the measurement process are the algorithms used in the analytical software to determine the parameters of the surface geometrical structure. Therefore, in doubtful cases, it is advisable to check the software used. In the case of measurements of the geometrical surface structure, programmable standards are used for this purpose, the characteristics of which are presented in standardization documents $[7,8]$ :

- PN-EN ISO 5436-2: 2013-04 Product geometry specifications (GPS) - Geometric surface structure: Profile method - Standards - Part 2: Programmed standards,

- PN-EN ISO 25178-71: 2013-06 Product geometry specifications (GPS) - Geometric surface structure: Spatial - Part 71: Programmed standards.

These norms define the concept of a programmable standard - as reference data or reference software intended to reproduce the mesurand value with known uncertainty in order to check the software used in the measuring instrument to calculate the measured value.

Norms define programmable standards of type F or S, used to check the software of measuring instruments in the field of filter algorithms and calculating parameters, which have been divided into two types: F1 and S1 as well as F2 and S2. Programmable standards of type F1 and S1 are data files representing a digital representation of the primary profile or surface. Programmed standards of the F2 or S2 type are reference software, which consists of coherent computer software in relation to the software, with which the measuring instrument is equipped. Few national metrological institutions (NMI) offer programmable standards of the F1 and S1 type, i.e. data files, and of the F2 and S2 type, i.e. reference software for checking commercial software, supplied with instruments for measuring the geometric structure of the surface. These institutions include:

- National Physical Laboratory (NPL) - United Kingdom,

- National Institute of Standards and Technology (NIST) - United States (experimental software),

- Physikalisch-Technische Bundesanstalt (PTB) - Germany.

With the use of programmed standards and reference software, it is possible to check the commercial software, with which the instrument used for measurements is equipped.

\section{Interlaboratory comparative tests}

An important element of confirming the reliability of measurements is the participation in interlaboratory comparative tests. It is an external tool for checking the quality of measurements. Examples of results from interlaboratory tests carried out for six optical and eight contact devices as part of the research project are shown in fig. 11. 


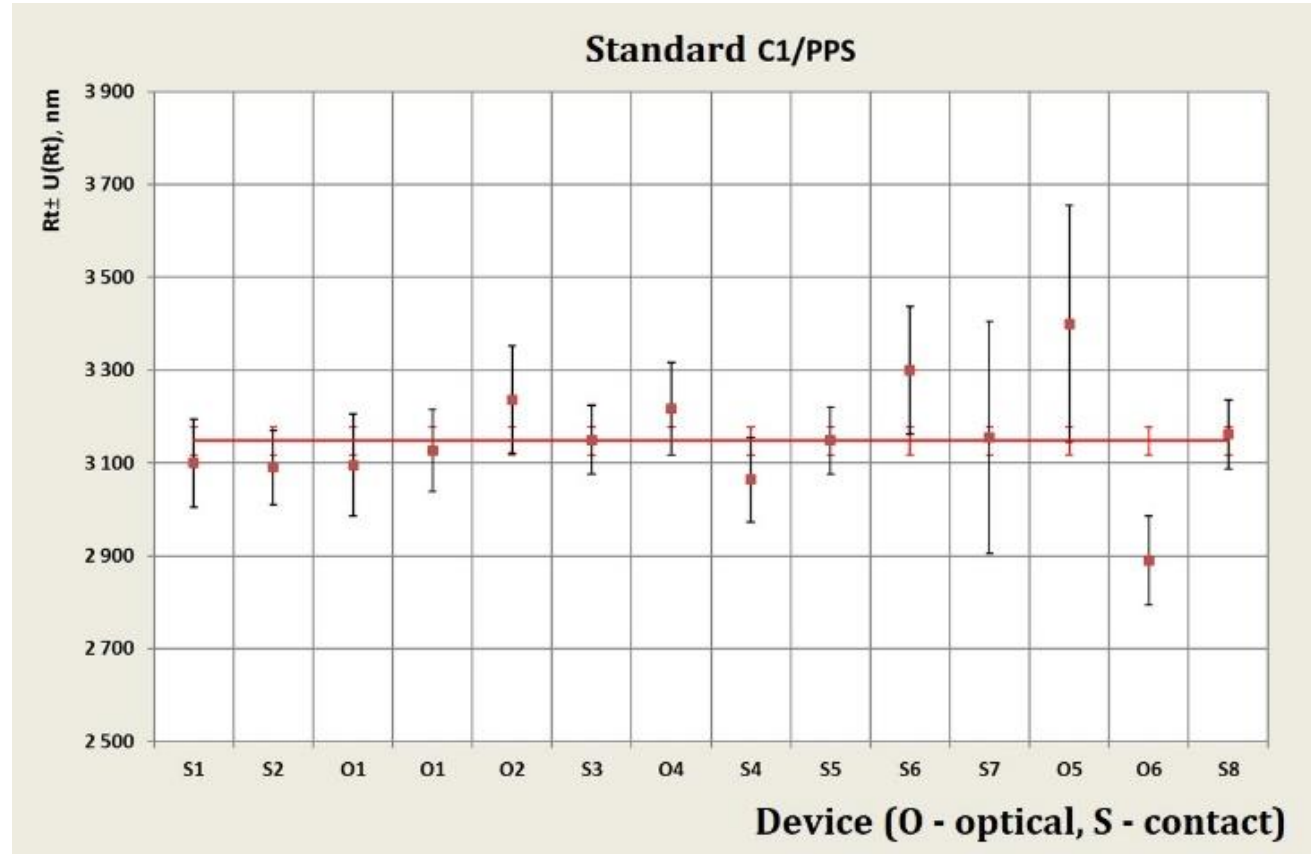

Fig. 11. Sample results of interlaboratory tests

\section{Summary}

Measurements of the geometric structure of the surface are among the most difficult in the group of measurements of geometric quantities. This is due to the variety of measurement methods used - their capabilities and limitations, the scale of inequalities measured - from nano to micro, as well as the impact of environmental conditions on the measurement process. Therefore, it is important to introduce and widely apply the principles of good measuring practice - both during measurements confirming the compliance with product specification requirements, and during research work.

The publication was based on the results obtained under the project No. PBS2/A6/20/2013 financed by the National Center for Research and Development "Research and assessment of the reliability of modern methods for measuring surface topography at the micro and nano scale".

The paper was financed from a project implemented by Fabryka Łożysk Tocznych - Kraśnik S.A., and financed from the European Union's operational program "Intelligent Development", which utilized the abovementioned results.

\section{REFERENCES}

[1] PN-EN ISO 25178-6 :2011 Specyfikacje geometrii wyrobów (GPS) - Struktura geometryczna powierzchni: Przestrzenna - Część 6: Klasyfikacja metod pomiaru struktury geometrycznej powierzchni.

[2] PKN- ISO/IEC Guide 99:2010 Międzynarodowy słownik metrologii - Pojęcia podstawowe i terminy z nimi związane (VIM).

[3] PN-EN ISO 25178-70:2014 SGP: Przestrzenna -Część 70: Wzorce materialne.

[4] Miller T., Adamczak S., Świderski J., Wieczorowski M., Łętocha A., Gapiński B. "Influence of temperature gradient on surface texture measurements with the use of profilometry". Bulletin of the Polish Academy of Sciences. 65, 1 (2017): 53-61.

[5] PN-EN ISO 25178-701:2010 Specyfikacje geometrii wyrobów (GPS) - Struktura geometryczna powierzchni: Przestrzenna - Część 701: Wzorcowanie i wzorce do przyrządów stykowych (z ostrzem odwzorowującym).

[6] PN-EN ISO 5436-1:2002 Specyfikacja geometrii wyrobów (GPS) - Struktura geometryczna powierzchni: Metoda profilowa - Wzorce - Część 1: Wzorce materialne.

[7] PN-EN ISO 5436-2:2013-04 Specyfikacje geometrii wyrobów (GPS) - Struktura geometryczna powierzchni: Metoda profilowa - Wzorce - Część 2: Wzorce programowane.

[8] PN-EN ISO 25178-71:2013-06 Specyfikacje geometrii wyrobów (GPS) - Struktura geometryczna powierzchni: Przestrzenna - Część 71: Wzorce programowane. 